\title{
Isochronal Study of Al-Mg, Al-Mn, and Al-Mn-Mg Alloys Using Electrical Resistivity and Thermoelectric Power
}

\author{
Ney José Luiggi Agreda* \\ Grupo de Física de Metales, GFM, Dpto. de Física, Escuela de Ciencias, \\ Núcleo de Sucre, Universidad de Oriente, Cumaná, Estado Sucre, Venezuela, \\ Código 17 Apartado Postal 299
}

Received: April 2, 2004; Revised: October 9, 2004

\begin{abstract}
We have studied the phase transformation kinetics occurring in aluminum alloys containing $\mathrm{Mn}, \mathrm{Mg}$, and $\mathrm{Mn}-\mathrm{Mn}-\mathrm{Mg}$ by means of electrical resistivity $(\rho)$ and thermoelectric power $(\Delta \mathrm{S})$. The alloy samples were annealed isochronally at temperatures ranging from ambient temperature to $615^{\circ} \mathrm{C}$. Both $\rho$ and $\Delta \mathrm{S}$ allowed the separation of several stages of transformation associated to either the precipitation or dissolution of phases that occur during the annealing process. The alloys containing Mn show a strong $\Delta \mathrm{S}$ growth or a marked $\rho$ drop between $450{ }^{\circ} \mathrm{C}$ and $550{ }^{\circ} \mathrm{C}$, linked to the precipitation of the $\mathrm{Mn}$-rich $\mathrm{Al}_{6}(\mathrm{Mn}, \mathrm{FE})$ equilibrium phase. While the $\mathrm{Mg}$ in aluminum generates a series of maxima and minima of both $\rho$ and $\Delta S$ associated to the pre-established precipitation sequence: GP Zones $\rightarrow \beta$ ' phase $\rightarrow \beta$ phase, a combination of effects ensues in the Mn- and Mg-containing alloys, the $\mathrm{Mg}$ effect being enhanced at temperatures below $350{ }^{\circ} \mathrm{C}$ and that of the Mn striking the same behavior above such temperature. Our study ascertains that the $\mathrm{Mg}$ speeds up the precipitation and lowers the activation energy of the $\mathrm{Al}_{6}(\mathrm{Mn}, \mathrm{Fe})$ phase, the latter having been evaluated by the multiple temperature method.
\end{abstract}

Keywords: Al-Mn, Al-Mg, Al-Mn-Mg Alloys, phase precipitation kinetics, electrical resistivity, thermoelectric power, aluminum alloys of the 3000 series

\section{Introduction}

Wrought aluminum alloys of the 3000 series have paramount commercial importance because of the gain in physical properties experienced by the aluminum matrix when alloying elements such as manganese (Mn) and magnesium $(\mathrm{Mg})$ are incorporated. Manganese has the virtue of prompting the precipitation of dispersoids responsible for the additional hardening sustained by the Al-Mn alloy, while magnesium contributes to that hardening, for concentrations used in this study, at the solid solution level ${ }^{1}$. Just as aluminum strength is altered by the presence of these alloying elements, other attributes of aluminum such as the electrical and thermoelectric properties are modified as well. Obviously, the presence of both of these alloying elements induces the combination of mechanisms producing such changes. The purpose of this paper is to study the effect that Mn and $\mathrm{Mg}$ alloying elements have on the transformation kinetics occurring when we subject the alloy to isochronal aging.

The techniques used were electrical resistivity $(\rho)$ and thermoelectric power $(\Delta S)$, both having a notorious sensitivity to the microstructural modifications associated to the diffusion of the alloying elements mentioned above ${ }^{2,3}$.

\section{Experimental Procedures}

\subsection{Alloys studied}

This study is performed on commercial 3003 alloys of Aluminios del Caroní S.A., ALCASA and binary Al-3 wt. (\%) Mg alloys produced by Pechiney-France, all originally in cast condition.

Likewise, in order to consider the effect of $\mathrm{Mg}$ over Mn precipitation, $\mathrm{Mg}$ was incorporated by fusion into the 3003 alloy at different proportions. This was carried out at the School of Metallurgy and Materials Sciences of Universidad Central de Venezuela. The chemical composition of the samples used is shown in Table 1.

\subsection{Thermal treatments}

Figure 1 shows the thermal treatment to which the samples are exposed. First, a homogenization treatment (HT) for 24 hours at $600{ }^{\circ} \mathrm{C}$ and then a quenching in a water and salt solution kept at $0{ }^{\circ} \mathrm{C}$. For the repeated isochronal studies, the samples are brought to the annealing temperature ( $\mathrm{Te}$ ) and maintained there for a constant period of time of 15 or 60 minutes. Each measurement is undertaken at the measure temperature (TM), set at $20^{\circ} \mathrm{C}$. It is worth noting that as the time necessary for the sample to remain at temperature Te is reduced, the condition of continuous treatment at a constant rate, indicated by the broken line in the graph, is approached.

All the runs performed involve isothermal annealing processes lasting 15 or 60 minutes at each temperature, processes which we designated as R1 and R2, respectively.

\subsection{Equipment used}

In order to measure the electrical resistivity, we used a controlled Sigmatest D 2068 microprocessor that gauges the conductivity of non magnetic materials in the range of 0.5 to $65 \mathrm{MS} / \mathrm{m}$ ( 1 to $112 \%$ IACS) with a measuring uncertainty of $\pm 1 \%$ of the measured value. This allows us to access resistivity values in the range of 1.54 to $200 \mu \Omega$.cm. The samples used were one-inch thick, $20 \times 20 \mathrm{~mm}^{2}$ squares. All measurements were performed at $20^{\circ} \mathrm{C}$, temperature at which $\mathrm{Mn}$, the main alloying element of the 3000 series alloys, shows low diffusivity in aluminum.

The gauging of thermoelectric power was carried out with a device designed by the Institut National des Sciences Appliquées de Lyon (INSA de Lyon), France, sensitive up to $0.01 \mu \mathrm{V} / \mathrm{K}$ and capable of measuring the thermoelectric power of laminar samples of various lengths with a measuring uncertainty of $0.2 \%$.

The heating at temperature $\mathrm{Te}$ is carried out in an air furnace with control of temperature of $\pm 5{ }^{\circ} \mathrm{C}$. 
Table 1. Chemical composition of the samples used in weight percent (wt. (\%)).

\begin{tabular}{cccccc}
\hline Alloy & $\mathrm{Mn}$ & $\mathrm{Fe}$ & $\mathrm{Si}$ & $\mathrm{Cu}$ & $\mathrm{Mg}$ \\
\hline 3003 & 1.10 & 0.67 & 0.28 & 0.1 & 0.004 \\
Al-Mn-0.5 Mg & $\sim 1.10$ & $\sim 0.67$ & 0.26 & 0.1 & 0.490 \\
Al-Mn-1.2 Mg & $\sim 1.10$ & $\sim 0.67$ & $\sim 0.28$ & $\sim 0.1$ & 1.150 \\
Al-Mg & & & & & 3.000
\end{tabular}

Note: $\mathrm{Ti}, \mathrm{Zr}$, and $\mathrm{Cr}$ in lower proportion at $0.01 \mathrm{wt}$. (\%) were also detected in the 3003 alloy.

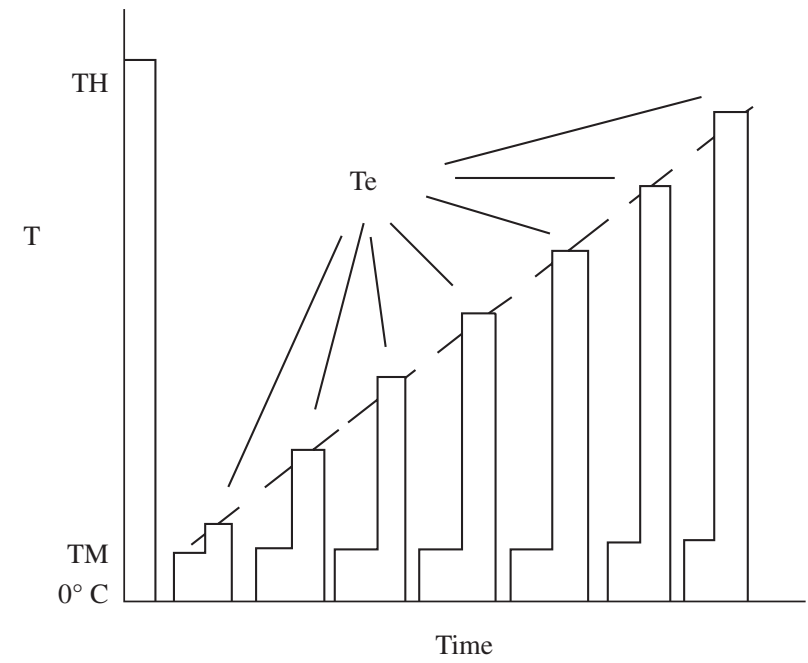

Figure 1. Diagram of the thermal treatment and measurements. HT: Homogenizing temperature. TM: Temperature at time of measuring. Te: Annealing temperature.

The reproducibility of the experience is warranted by selecting homogenized samples having properties whose measured values range within $1 \%$.

\section{Theoretical Aspects}

The differential equation for the isothermal study of transformation kinetics involves the transformed fraction $\mathrm{Y}$, the reaction constant $\mathrm{K}$, and the kinetic or conversion function $\mathrm{G}$. It is customary to assume $\mathrm{K}$ as a function of temperature $\mathrm{K}(\mathrm{T})$ and $\mathrm{G}$ as a function of conversion $\mathrm{G}(\mathrm{Y})$, so that both functions are assumed independent, allowing us to write a simplified kinetic equation as

$$
\frac{d Y}{d t}=K(T) G(Y)
$$

In integral form this equation is written as,

$$
\mathrm{g}(\mathrm{Y})=\int_{0}^{\gamma} \frac{d Y}{G(Y)}=\int_{0}^{t} K(T) d t
$$

The kinetic function $\mathrm{G}(\mathrm{Y})$ is defined on the basis of a series of empirical models ${ }^{4-8}$, while for thermally activated processes, $\mathrm{K}$ follows an Arrhenius relation.

$$
K(T)=K_{0} \exp \left(-\frac{Q}{R T}\right)
$$

where the pre-exponential factor $\mathrm{K}_{0}$ and activation energy $\mathrm{Q}$ are characteristic parameters of the transformation. However, it is necessary to mention the ambiguity that arises when different kinetic models are used to characterize the same transformation. This situ- ation has led many authors to resort to the isoconversion method ${ }^{9}$, which lay aside the use of such models to determine the characteristic parameters of transformation kinetics.

A method seldom used to evaluate the energy of activation is that of two temperatures ${ }^{10,11}$, involving two transformation kinetics, or that of multiple temperatures, involving more than two kinetics, where the principle of isoconversion is basically applied by defining the temperatures at which the same conversion or transformed fraction for different heating rates is kept. This is evidenced in the present research by means of our isochronal thermal treatment, which involves a series of isothermal annealing techniques during a fixed time (see Figure 1). For two subsequent isothermal annealing treatments at $T_{1}$ and $\mathrm{T}_{2}$ temperatures, and considering that no structural modification occurs during the temperature change from $\mathrm{T}_{1}$ to $\mathrm{T}_{2}$, the transformed fraction at the end of the first isothermal annealing at temperature $\mathrm{T}_{1}$ and at the beginning of the second isothermal annealing at temperature $\mathrm{T}_{2}$ remains unchanged. Hence from Equation 2 we can write:

$$
\begin{aligned}
& g_{1}(Y)=K_{1} t_{1} \leftrightarrow K_{1}=K_{0} \exp \left(-Q_{1} / R T_{1}\right) \\
& g_{2}(Y)=K_{2} t_{2} \leftrightarrow K_{2}=K_{0} \exp \left(-Q_{2} / R T_{2}\right)
\end{aligned}
$$

In Equation $4, t_{1}$ and $t_{2}$ times constitute the necessary time for obtaining the same conversion $\mathrm{Y}$ at temperatures $\mathrm{T}_{1}$ and $\mathrm{T}_{2}$. On the basis that no important transformation occurs during the change of $\mathrm{T}, g_{1}(Y)=g_{2}(Y)$, and considering:

$Q_{1}=Q_{2}=Q$

we can write,

$$
Q=R \frac{T_{1} T_{2}}{T_{1}-T_{2}} \ln \left(\frac{t_{2}}{t_{1}}\right)
$$

an expression similar to that reported in the literature ${ }^{10}$,

$$
Q=R \frac{T_{1} T_{2}}{T_{1}-T_{2}} \ln \left(\frac{\tau_{1}}{\tau_{2}}\right)
$$

where $\tau_{\mathrm{n}=1 / \mathrm{kn}}$ and where Equation 6 may be obtained from Equation 7 by setting an adequate reaction model. This is evident in the first order reaction model or in the Johnson-Mehl-Avrami model with $\mathrm{N}=1^{5,11}$, which, as a solution to Equation 1 proposes

$$
Y=1-\exp (-K t)
$$

Also, as in Reference 10, assuming that the transformation follows a kinetic of the first order, the following relation is deduced specifically for resistive studies.

$$
\frac{\rho(t)-\rho(\infty)}{\rho(0)-\rho(\infty)}=\exp \left(-\frac{t}{\tau}\right)
$$

the reaction constant inverse being $\tau=\mathrm{K}^{-1}$, thus allowing us to write,

$$
Q=R \frac{T_{1} T_{2}}{T_{1}-T_{2}}\left[\ln \left(\frac{d \rho}{d t}\right)_{T_{1}}-\ln \left(\frac{d \rho}{d t}\right)_{T_{2}}\right]
$$

Equations 7 and 10 are of a modeling nature since they follow a specific kinetic model, while Equation 6 has an isoconversional nature. Now, if we consider many isothermal kinetics, we could establish a Temperature-time continuum so that

$$
\frac{d \rho}{d t}=\frac{d \rho}{d T} \frac{d T}{d t}
$$




$$
Q=R \frac{T_{1} T_{2}}{T_{2}-T_{1}}\left[\ln \left(\frac{d \rho}{d T}\right)_{T_{2}}-\ln \left(\frac{d \rho}{d T}\right)_{T_{1}}+\ln \left(\frac{(d T / d t)_{T_{2}}}{(d T / d t)_{T_{1}}}\right)\right]
$$

The last term of Equation 12 reflects the change in temperature rate with time, allowing us to incorporate the experimental temperature-versus-time path to our isochronal studies. The typical case is one of continuous heating, where $d T / d t$ is constant. However, any temperature-time ramp may be incorporated through that term.

The applicability of Equation 12 is only restricted to resistivity measurement. A more general expression applicable also to an arbitrary thermal path and to other measuring techniques can be deduced by means of the general isoconversional relation for non-isothermal studies propounded by Luiggi ${ }^{9}$,

$$
\operatorname{In}\left(\frac{T^{N}}{\beta}\right)-\frac{Q}{R T}=\text { constant }
$$

where $\beta$ is the heating rate. For two kinetics with heating ratios $\beta_{1}$ and $\beta_{2}$, we obtain the same transformed fraction $Y$ at temperatures $T_{1}$ and $T_{2}$, so that

$$
\ln \left(\frac{T_{1}^{N}}{\beta_{1}}\right)-\frac{Q_{1}}{R T_{1}}=\ln \left(\frac{T_{2}^{N}}{\beta_{2}}\right)-\frac{Q_{2}}{R T_{2}}
$$

and, considering that $Q_{1}=Q_{2}=Q$, we get:

$$
Q=R \frac{T_{1} T_{2}}{T_{2}-T_{1}}\left[\ln \left(\frac{T_{2}^{N}}{T_{1}^{N}}\right)+\ln \left(\frac{\beta_{1}}{\beta_{2}}\right)\right]
$$

where $\beta_{\mathrm{i}=(\mathrm{d} T / \mathrm{dt}) \pi i}$. The right side of Equation 15, like that of Equation 12, would allow the consideration of any temperature-time ramp that might be contemplated experimentally.

\section{Results and Discussion}

\subsection{Alloy: Al-1.1 wt. (\%) Mn}

Figures $2 \mathrm{a}$ and $2 \mathrm{~b}$ show the electrical resistivity and its derivative with respect to the temperature of the 3003 alloy. Figure 2 shows slight variations of $\rho$ for temperatures below $400{ }^{\circ} \mathrm{C}$ for $\mathrm{R} 1$ and below $350^{\circ} \mathrm{C}$ for $\mathrm{R} 2$; this is followed by an important resistivity drop whose minimum places itself in the neighborhood of $555^{\circ} \mathrm{C}$ for R 1 and $525^{\circ} \mathrm{C}$ for $\mathrm{R} 2$, followed by an increase in resistivity.

Such behavior is explained by the diffusion process activated by the temperature increase. For low temperatures, a structural rearrangement is produced where the $\mathrm{Si}$ atoms are the main participants. In this stage the $\mathrm{Fe}$ and $\mathrm{Mn}$ atoms take part in a smaller proportion; this is easily inferred from the magnitude reached by $\rho$ at those temperatures. The contribution of each atom kind to the total resistivity can be deduced using Table 2 of Reference 2. The important depression occurs due to the solid solution depletion prompted mainly by the massive precipitation of $\mathrm{Mn}$ in the form of $\mathrm{Al}_{6}(\mathrm{Fe}, \mathrm{Mn})$ phase. The subsequent growth corresponds to this phase becoming a solid solution. The time at each temperature magnifies the precipitation of each alloying element, precipitation which, in the particular case of $\mathrm{Mn}$, does not settle completely for the selected annealing runs at each temperature. For the same reason we observe that the shorter the annealing time, the higher the temperature at which the minimum appears. This is illustrated in Figure $2 \mathrm{~b}$, where the absolute maxima of the derivative located at $475^{\circ} \mathrm{C}$ and $450{ }^{\circ} \mathrm{C}$ for $\mathrm{R} 1$ and $\mathrm{R} 2$, respectively represent the temperatures at which the highest precipitation rate of $\mathrm{Mn}$ is produced.

Figures 3a and 3b reproduce the study of the 3003 alloy using thermoelectric power. Figure 3a plots $\Delta \mathrm{S} v s$. T, a slight variation of the property appearing for temperatures below $350{ }^{\circ} \mathrm{C}$; an important increase then ensues, reaching a maximum at $550{ }^{\circ} \mathrm{C}$ for $\mathrm{R} 1$ and at $523^{\circ} \mathrm{C}$ for $\mathrm{R} 2$, in perfect agreement with the previous resistivity study. Figure $3 \mathrm{~b}$ shows the derivative of thermoelectric power $v s$. T, from which it can be observed that the maximum rate of precipitation is obtained at $500{ }^{\circ} \mathrm{C}$ for $\mathrm{R} 1$ and in the vicinity of $475^{\circ} \mathrm{C}$ for $\mathrm{R} 2$, thus evidencing the decisive effect of $\mathrm{Mn}$ precipitation for temperatures above $350{ }^{\circ} \mathrm{C}$.

\subsection{Al-3 wt. (\%) Mg Alloy}

Figure $4 \mathrm{a}$ shows electrical resistivity changes in function of the temperature, where three depressions and several maxima are detected, depending on whether we contemplate R1 or R2. The interpretation of this graph is as follows: The first depression corresponds to the dissolution of the Guinier-Preston zones formed during the first annealing treatments performed at the lowest temperatures; it reaches its final point at $100{ }^{\circ} \mathrm{C}$, point at which the $\mathrm{Mg}$ starts a process of precipitation as a $\beta$ ' phase, reaching $350{ }^{\circ} \mathrm{C}$ for the $\mathrm{R} 1$ treatment but just up to $250{ }^{\circ} \mathrm{C}$ for the $\mathrm{R} 2$ treatment. The dissolution of this phase extends itself up to $400{ }^{\circ} \mathrm{C}$, both for R1 and R2. The precipitation of the $\beta$ phase occurs between 400 and $460{ }^{\circ} \mathrm{C}$, its dissolution ceasing at $550{ }^{\circ} \mathrm{C}$. The subsequent variation is associated to the sample's entering into solution and possible softening. This general comportment has been reported by Starink and Zahra ${ }^{12}$, by

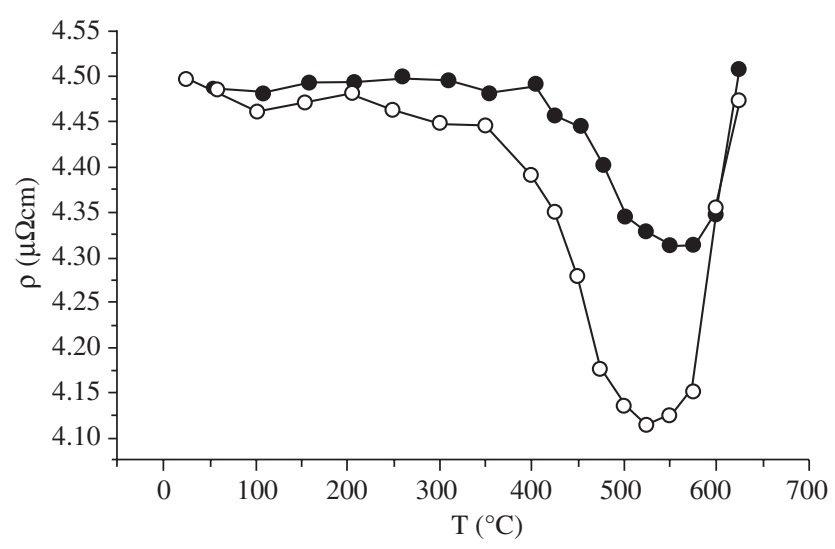

(a)

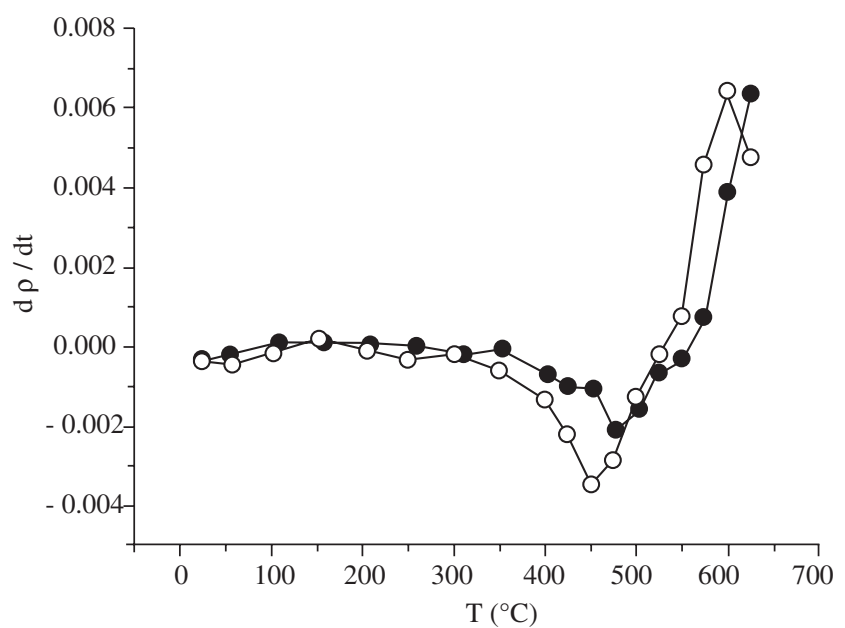

(b)

Figure 2. a) Electrical resistivity of the 3003 alloy in function of the temperature, : 15-minutes $\bigcirc: 60$-minutes annealing treatment times; b) Derivative of the electrical resistivity with respect to temperature for the 3003 alloy,

: 15 -minutes $\bigcirc: 60$-minutes annealing treatment times. 


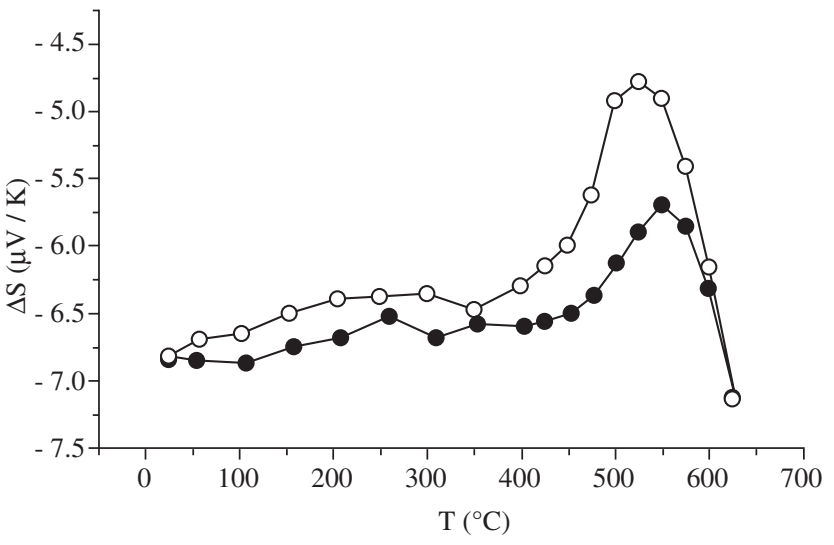

(a)

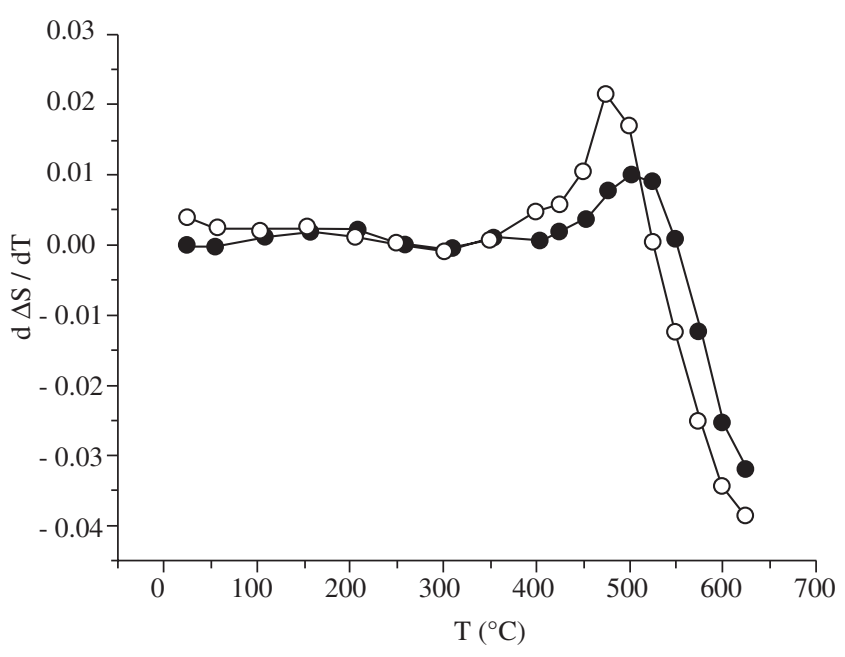

(b)

Figure 3. a) Thermoelectric power in function of the temperature of the 3003 alloy, 15 -minutes $\bigcirc$ : 60-minutes annealing treatment times; b) Derivative of the thermoelectric power with respect to temperature for the 3003 alloy, 15 -minutes $\bigcirc: 60$-minutes annealing treatment times.

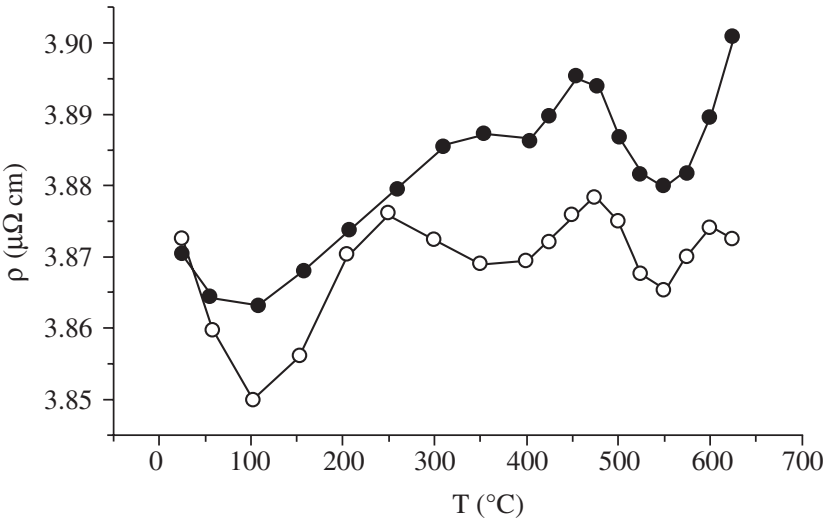

(a)

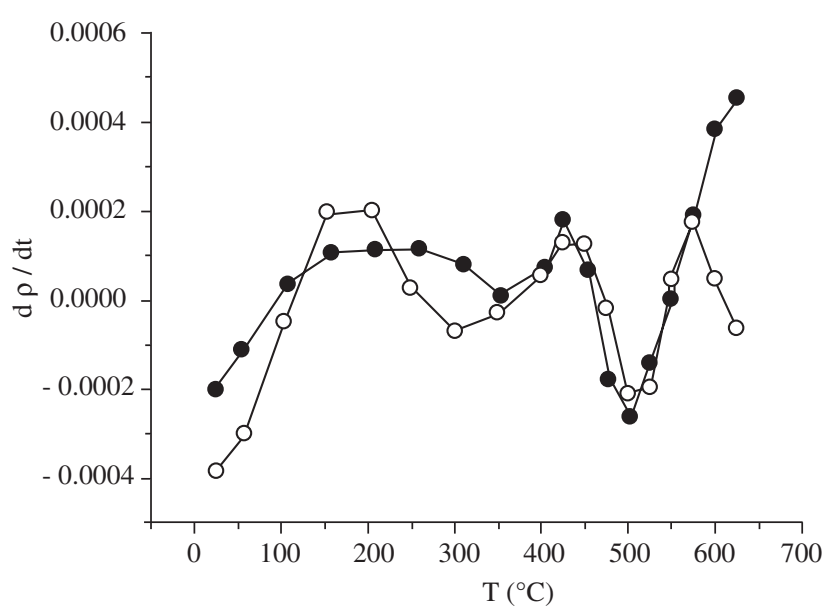

(b)

Figure 4. a) Electrical resistivity of an $\mathrm{Al}-3 \mathrm{wt}$. (\%) $\mathrm{Mg}$ in function of the temperature, $\bigcirc$ : 15-minutes $\bigcirc$ : 60-minutes annealing treatment times; b) Derivative of the electrical resistivity with respect to temperature for the Al-3 wt. (\%) Mg alloy, $\mathbf{0}: 15$-minutes $\bigcirc$ : 60-minutes annealing treatment times.

Bouchear, Hamana and Laoui ${ }^{13}$, and by Luiggi and Betancourt ${ }^{14}$ for alloys with a higher $\mathrm{Mg}$ content.

It is important to notice how the kinetics thus obtained clearly outline the temperature ranges where $\beta$ ' and $\beta$ phases are formed and dissolved. These ranges are confirmed in Figure $4 \mathrm{~b}$, which shows the derivative of curve $4 \mathrm{a}$.

Figures $5 \mathrm{a}$ and $5 \mathrm{~b}$ further ratify this behavior, arrived at by means of thermoelectric power. The process of precipitation and dilution of the Guinier-Preston zones and those of the $\beta$ ' and $\beta$ phases are manifested by the appearance of characteristic depressions and peaks, their location being in accordance with those reported by resistivity.

\subsection{Al-Mn-0.5 Mg Alloy}

Figures $6 a$ and 7 a show the electrical resistivity $(\rho)$ and the thermoelectric power (PTE) in function of the temperature. The behavior of these properties is qualitatively similar to the behavior observed in the 3003 alloy (Figures 2 and 3). The most striking differences are seen at temperatures below $400{ }^{\circ} \mathrm{C}$ owing to the effect of precipitation of $\mathrm{Mg}$. This alloying element has a specific resistivity up to 5 times lower than that of $\mathrm{Mn}$, and an intrinsic TEP both positive and 2.8 times lower that the Mn intrinsic TEP, which is negative ${ }^{15}$. All this, along with the fact that the process of transformation occurs by diffusion and that the $\mathrm{Mg}$ is kinetically more active than $\mathrm{Mn}$, allows us to explain why, at lower temperatures, $\mathrm{Mg}$ has a greater influence over the kinetics of transformation. At high temperatures the profuse precipitation of Mn masks the precipitation and dissolution of the $\beta$ phase observed in the binary Al-3 wt. (\%) Mg (Figures 4a and 5a). Again, this fact is explained because the specific electrical resistivity and thermoelectric power of $\mathrm{Mg}$ in $\mathrm{Al}$ are relatively smaller than those reported for the $\mathrm{Mn}$ in Al. It is also noticeable, as shown by Figures 6a and $7 \mathrm{a}$ and their derivatives (Figures $6 \mathrm{~b}$ and $7 \mathrm{~b}$ ) that the absolute maxima in the alloy containing $\mathrm{Mg}$ appear at lower temperatures, which can be interpreted as a progress in $\mathrm{Mn}$ precipitation.

\subsection{Al-Mn-1.2 Mg Alloy}

Figures 8 and 9 illustrate the results for the alloy containing $1.2 \mathrm{wt}$. (\%) Mg. Here, the participation of both alloying elements at different ranges of temperatures is, again, rendered evident. The $\mathrm{Mg}$ prevails at low temperatures and the $\mathrm{Mn}$ at the high ones. The precipitation of the former plays a delaying role in the precipitation of the equilibrium phase of the Mn-rich alloy. Again, at high temperatures, 


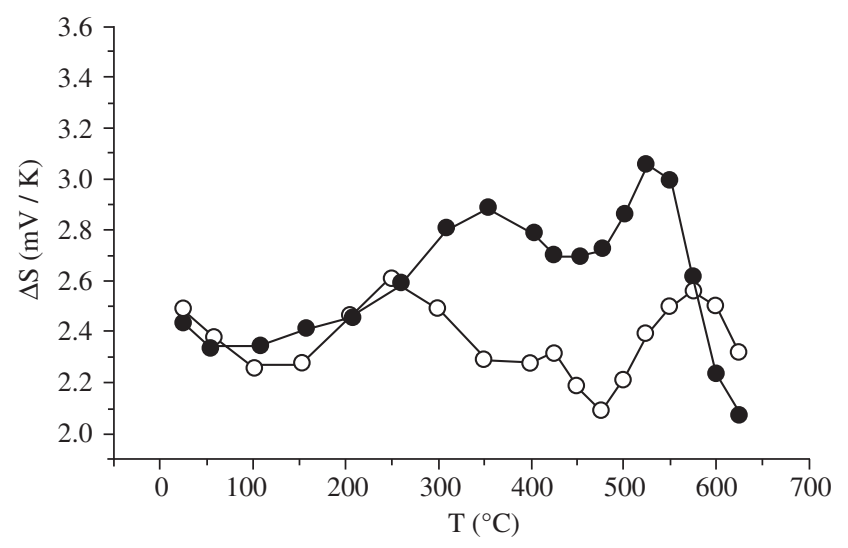

(a)

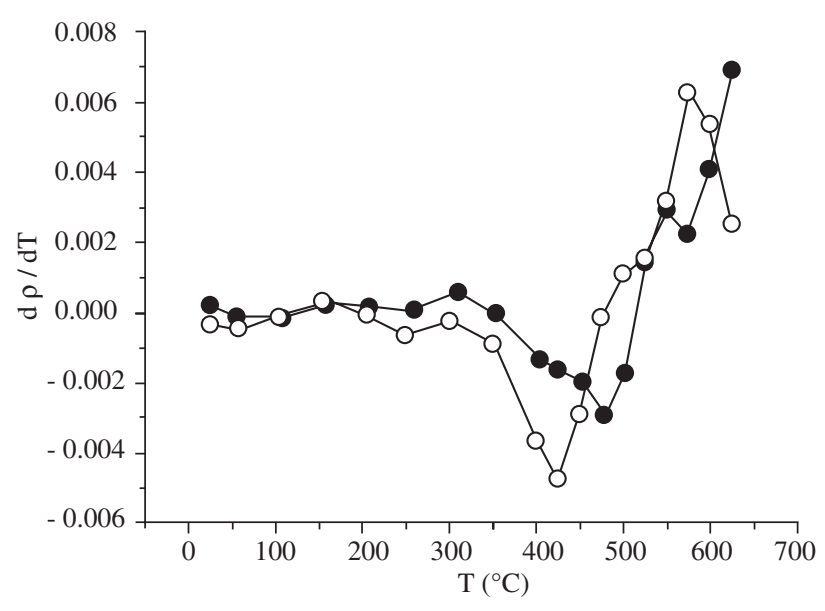

(b)

Figure 5. a) Thermoelectric power of an Al-3 wt. (\%) Mg alloy in function of the temperature 1 : 15-minutes $\bigcirc$ : 60-minutes annealing treatment times; b) Derivative of the thermoelectric power with respect to temperature for the Al-3 wt. (\%) Mg alloy, 15 -minutes $\bigcirc$ : 60-minutes annealing treatment times.

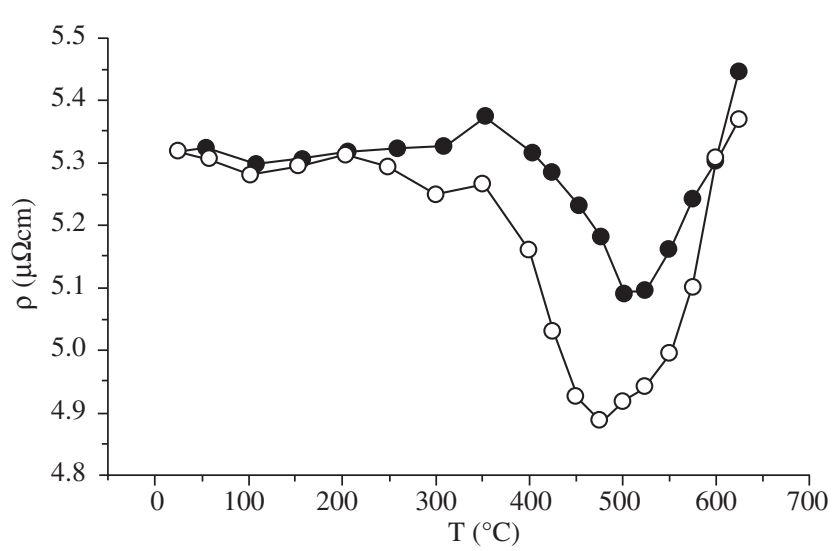

(a)

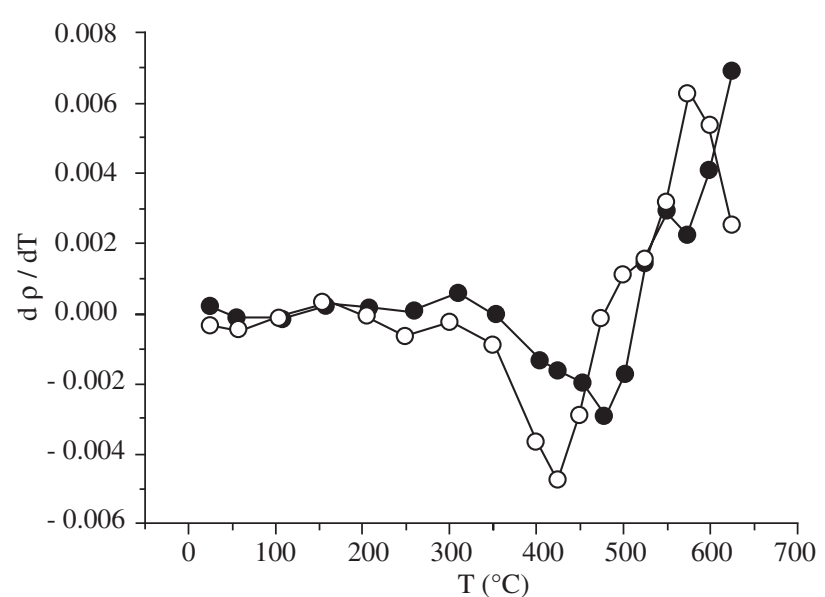

(b)

Figure 6. a) Electrical resistivity of the Al-Mn- $0.5 \mathrm{Mg}$ alloy in function of the temperature, 15 -minutes $\mathrm{O}$ : 60-minutes annealing treatment times; b) Derivative of the electric resistivity with respect to temperature for the Al-Mn- $0.5 \mathrm{Mg}$ alloy, $\bullet: 15$-minutes $\mathrm{O}$ : 60-minutes annealing treatment times.



(a)

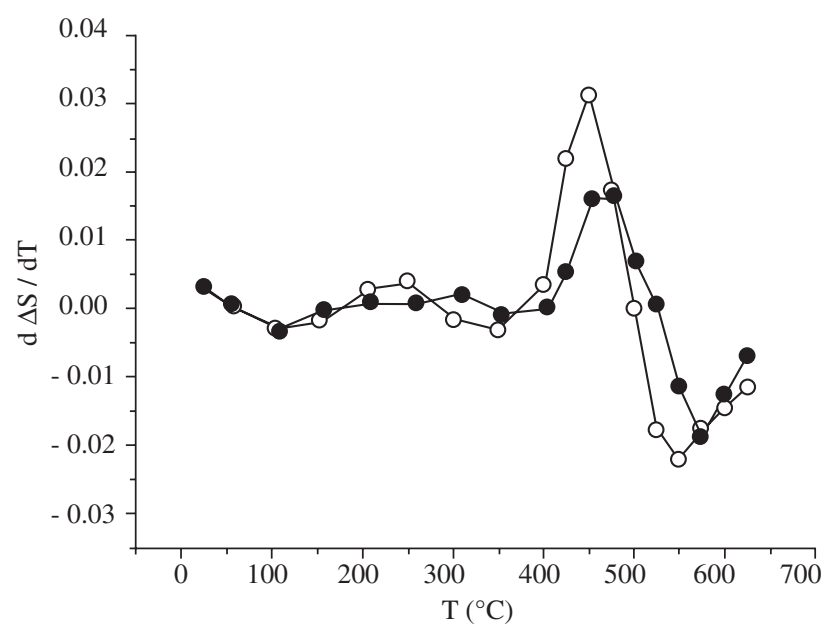

(b)

Figure 7. a) Thermoelectric power of the Al-Mn-0.5 Mg alloy in function of the temperature, $:$ : 15-minutes $\bigcirc$ : 60 -minutes annealing treatment times; b) Derivative of the thermoelectric power with respect to temperature for the Al-Mn- $0.5 \mathrm{Mg}$ alloy, 0 : 15-minutes $\mathrm{O}$ : 60 -minutes annealing treatment times. 


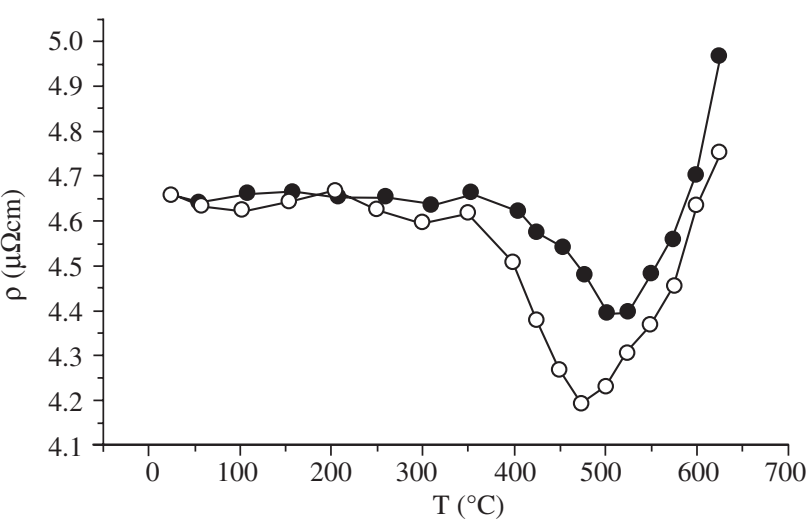

(a)

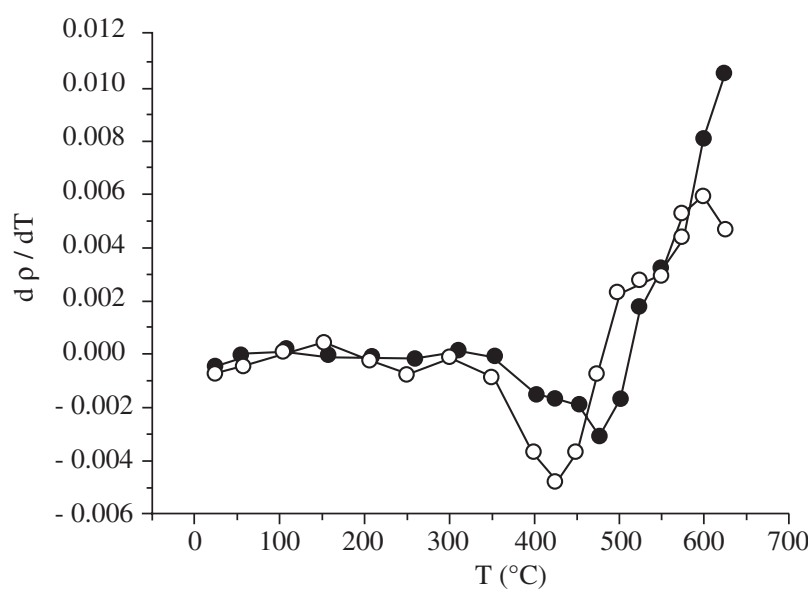

(b)

Figure 8. a) Electrical resistivity of the Al-Mn-1.2 Mg alloy in function of the temperature, 15 -minutes $\bigcirc: 60$-minutes annealing treatment times; b) Derivative of the electrical resistivity with respect to temperature for the Al-Mn-1.2 Mg alloy,

15-minutes $0: 60$-minutes annealing treatment times.



(a)

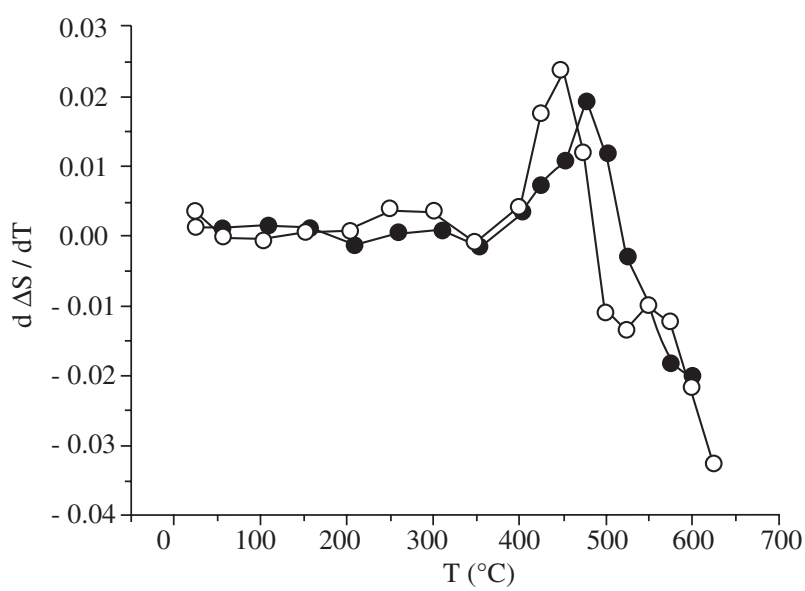

(b)

Figure 9. a) Thermoelectric power of the Al-Mn-1.2 Mg alloy in function of the temperature tive of the thermoelectric power with respect to temperature for the Al-Mn-1.2 Mg alloy,

15-minutes $\bigcirc:$ 60-minutes annealing treatment times; b) Deriva15-minutes $\bigcirc: 60$-minutes annealing treatment times.

the precipitation of the $\beta$ phase ${ }^{14}$ is masked by the precipitation of the $\mathrm{Al}_{6}(\mathrm{Fe}, \mathrm{Mn})$ phase.

\subsection{Application of the multiple-temperature method to evaluate the activation energy}

To wrap up this study we proceeded to determine how the presence of $\mathrm{Mg}$ affects the precipitation kinetics of $\mathrm{Mn}$ in the different alloys. For that, using the data associated to the derivative with respect to both $\rho$ and TEP, we assessed the precipitated fraction $Y$ of the transformation corresponding to the largest absolute depression both in $\rho$ and $\Delta \mathrm{S}$ for the 3003 , Al-Mn- $0.5 \mathrm{Mg}$ and $1.2 \mathrm{Mg}$ alloys.

The slope of $Y$ is obtained by considering the area under the curve of the derivative belonging to the property measured in the temperature range where the transformation occurs, normalizing it then to the total area and determining the temperatures at which the transformed fraction remains constant. Once these isoconversional temperatures are known, only the $\beta_{\mathrm{i}}$ contribution remains to be determined in order to evaluate the activation energy of the $\mathrm{Al}_{6}(\mathrm{Mn}, \mathrm{Fe})$ phase.

Although we could have evaluated parameter $\beta$ in a relative fashion by utilizing the activation energy value of the stable phase $\mathrm{Al}_{6}(\mathrm{Mn}, \mathrm{Fe})$, previously established to be $35.52 \mathrm{Kcal} / \mathrm{mol}$ in the $435^{\circ} \mathrm{C}$ and $515{ }^{\circ} \mathrm{C}$ range ${ }^{16}$, we preferred, once the isoconversion temperatures were known, to use the graphs of the derivatives of the property with respect to temperature and determine the second term of Equation 15 from the following relation:

$$
\ln \frac{\beta_{1}}{\beta_{2}}=\ln \left[\frac{\left(\frac{d \psi}{d T}\right)_{T 2}}{\left(\frac{d \psi}{d T}\right)_{T 1}} \times \frac{\left(\frac{d \psi}{d t}\right)_{T 1}}{\left(\frac{d \psi}{d t}\right)_{T 2}}\right]
$$

where $\psi$ represents the electrical resistivity or the thermoelectric power, while the second term within brackets represents the associated slopes to isothermal kinetics ratio at temperatures $T_{1}$ and $T_{2}$, respectively.

The considerations to assess the activation energy in this research are the following:

1. Our values are valid for isothermal kinetics of similar slope.

2. In principle, our model is checked for kinetics of the first order, as addressed in Ref. 10; this sets $\mathrm{N}$ as equal to 1, though $\mathrm{N}$ may be changed and its effect on the kinetics determined.

Figure 10 summarizes these results. It shows the activation energy (Q) of the $\mathrm{Al}_{6}(\mathrm{Mn}, \mathrm{Fe})$ phase in function of the extent of conversion or transformed fraction (Y), which is calculated using Equation 15, Equation 16 and the previous considerations. These results are pointed out with empty symbols in Figure 10, showing, for all the alloys under study, that $\mathrm{Q}$ varies with the conversion extent $\mathrm{Y}$. This behavior reveals the complexity of the reaction mechanism occurring 


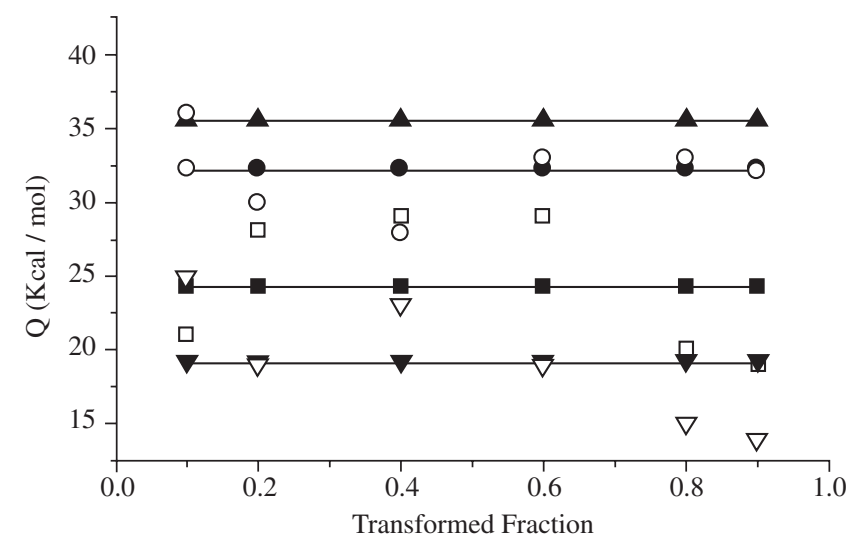

Figure 10. Activation energy of the $\mathrm{Al}_{6}(\mathrm{Mn}, \mathrm{Fe})$ phase in function of the transformed fraction, $\mathbf{\Delta}$ : Referential result obtained in Ref. 16. $\bigcirc$ Activation energy obtained from the 3003 alloy Average value of Q for the 3003 alloy . $\square$ Activation energy obtained from the Al-Mn-0.5 Mg alloy. Average value of $\mathrm{Q}$ for the Al-Mn- $0.5 \mathrm{Mg}$ alloy. $\nabla$ Average activation energy obtained from the Al-Mn-1.2 Mg alloy. $\nabla$ Average value of Q obtained from the Al-Mn-1.2 Mg alloy.

during the phase transformation processes, seeming a typical comportment in the studies carried out using isoconversional methods $\mathrm{s}^{4,14}$. The resulting dependence of $\mathrm{Q}$ on $\mathrm{Y}$ contrasts with the invariability of Q reported when empirical models are used. In those cases, the kinetic parameters, $\mathrm{K}_{0}, \mathrm{Q}$ and $\mathrm{G}(\mathrm{Y})^{14}$, are fit along the whole extent of $Y$ to obtain the best correspondence between the experimental and the theoretical $\mathrm{Y}$ values, reporting only one $\mathrm{Q}$ value for the entire $\mathrm{Y}$ range having been reported. Mathematically this situation can be reproduced by averaging the $\mathrm{Q}$ values obtained for each alloy, using $\rho$ and $\Delta S$ along the entire $Y$ extent. The horizontal lines in Figure 10 correspond to the average $\mathrm{Q}$ values. We report results of activation energies of $32.2 \mathrm{Kcal} / \mathrm{mol}, 24.3 \mathrm{Kcal} / \mathrm{mol}$, and $19.2 \mathrm{Kcal} / \mathrm{mol}$ for the $\mathrm{Al}_{6}(\mathrm{Mn}, \mathrm{Fe})$ phase, as measured in the $3003, \mathrm{Al}-\mathrm{Mn}-05 \mathrm{Mg}$, and $\mathrm{Al}-$ Mn-1.2 Mg alloys, respectively. Notice the good agreement of our result for the 3003 alloy with those reported in Ref. 16, also shown in Figure 10. There is also an equally remarkable match between our results and those presented by Goel et al. 17 in their work on binary $\mathrm{Al} 1 \mathrm{wt}$. (\%) $\mathrm{Mn}$ and ternary alloys to which $\mathrm{Cu}$ and $\mathrm{Fe}$ have been added. We observe that as the $\mathrm{Mg}$ concentration increases, the activation energy values obtained become lower, allowing us to point out that the effect of $\mathrm{Mg}$ on the $\mathrm{Al}_{6}(\mathrm{Mn}, \mathrm{Fe})$ precipitation constitute a reduction of its activation energy.

\section{Conclusions}

We have studied the effect of $\mathrm{Mg}$ on a 3003 aluminum alloy subjecting it to isochronal annealing treatments of 15 and 60 minutes at fixed temperatures, and have observed that:

- Both the resistivity and the thermoelectric power are highly sensitive to the structural modifications;

- Our study of Al-Mg alloys corroborates the sequence of precipitation and dissolution of phases containing $\mathrm{Mg}$ reported by other authors using different study techniques ${ }^{12}{ }^{14}$. As the temperature increases the phases follow the sequence: G-P Zones, $\beta$ ' phase and $\beta$ phase;

- In the 3003 alloy it is confirmed the precipitation of light elements as $\mathrm{Si}$ at low temperatures, whilst at high temperatures, characterized by important $\rho$ and $\Delta \mathrm{S}$ changes, Mn precipitates forming the $\mathrm{Al}_{6}(\mathrm{Fe}, \mathrm{Mn})$ phase;

- The effect of $\mathrm{Mg}$ on the precipitation kinetics of the Al-Mn$\mathrm{Mg}$ alloys is more noticeable at low temperatures than at high temperatures, because an abundant Mn precipitation occurring at high temperatures masks the $\mathrm{Mg}$ effect. $\mathrm{Mg}$ speeds up the precipitation of $\mathrm{Mn}$, causing a decrease of the $\mathrm{Al}_{6}(\mathrm{Fe}, \mathrm{Mn})$ phase activation energy value from $32.2 \mathrm{Kcal} / \mathrm{mol}$ in the 3003 alloy to 24.3 and to $19.2 \mathrm{Kcal} / \mathrm{mol}$ in the $\mathrm{Al}-\mathrm{Mn}-0.5 \mathrm{Mg}$ and the Al-Mn-1.2 Mg alloys, respectively.

\section{Acknowledgements}

This research was supported by the Consejo de Investigación de la Universidad de Oriente through Project No CI. 5-1002-0938 UDO. The author is also grateful to Carlos Mota and his company Traduce, C.A. for translation assistance.

\section{References}

1. American Society for Metals. ALUMINUM. Properties and Physical Metallurgy. Edited by Hatch JE. Metals Park, Ohio. USA. 1984; 359.

2. Luiggi N. Isothermal Precipitation of Commercial $3003 \mathrm{Al}$ alloys Studied by Thermoelectric Power. Metall. Mat. Trans. B. 1997; 28B(1):125-133.

3. Móricz I, Szabó IA, Hordóz M, Beke DL, Kedves FJ. The effect of Fe and $\mathrm{Si}$ on the precipitation behavior of $\mathrm{Mn}$ in aluminum. Eng. Mater. 1990; 44-45:65-270.

4. Vyazovkin S, Wight Ch. Isothermal and Nonisothermal Reaction Kinetics in Solids: In Search of Ways toward Consensu. J. Phys. Chem. A. 1997; 101(39):8279-8284.

5. Burke J. La cinétique des changements de phase dans les metaux. Masson et Cie Éditeurs. Paris. 1968; 144.

6. Christian JW. The Theory of Transformations in Metals and Alloys. Part I. Pergamon Press. Oxford. 1975; 17-20, 542.

7. Fujita FE. On the kinetics of precipitation in alloys. J. Phys. Soc. Japan. 1964; 19(5):640-651.

8. Damask A, Danielson G, Dienes G. A kinetic theory in dilute solid solutions: Application to the precipitation of carbon and nitrogen in $\alpha$-iron. Acta Metall. 1965; 13:973-89.

9. Luiggi N. Comments on the Analysis of Experimental Data in Nonisothermal Kinetics. Metall. Mat. Trans. A. 2003; 34A(11):2679-2682.

10. Miki VI, Warlimont H. Morphology and Kinetics of Precipitation Processes in Aluminium - Rich Al - Fe - and Al - Fe - Si Alloys. Z. Metallkde. 1968; 59(4):254-264.

11. Luiggi N, Betancourt AE. Multiphase Precipitation of Carbides in Fe-C Systems: Part I. Model based upon Simple Kinetic Reactions. Metall. Mat. Trans. B. 1994; 25B(4):917-925.

12. Starink MJ, Zahra AM. The Kinetics of Isothermal $\beta$ ' Precipitation in Al-Mg Alloys. J. Mat. Sci. 1999; 34:1117-1127.

13. Buchear M, Hamana D, Laoui T. GP Zones and Precipitate Morphology in Aged Al - Mg Alloys. Phil. Mag. A. 1996; 37(6): 1733-740.

14. Luiggi N, Betancourt M. On the Non-Isothermal Precipitation of the $\beta$ ' and $\beta$ Phases in $\mathrm{Al}$ - 12.6 Mass \% Mg Alloys Using Dilatometric Techniques. J. Therm. Analy. Cal. 2003; 74(3):883-894.

15. Borrelly R, Merle P, Adenis D. Seebeck. Effect of Precipitation in 3004. Light Metals. 1989;703-711.

16. Luiggi N. Analysis of Thermoelectric Power Measurements in the Study of Precipitation Kinetics in 3003 Alloy. Metall. Mat. Trans. B. 1997; 28B(1):149-159.

17. Goel DB, Ferrer P, Warlimont H. Precipitation Characteristics of aluminium-manganese (copper,iron) alloys. ALUMINIUM. 1974; 50(8): $511-516$. 